\title{
ОПТИМІЗАЦІЯ ПРОЦЕСУ РЕЄСТРАЦІЇ ТА СПИСАННЯ ЛАБОРАТОРНОГО ВИТРАТНОГО МАТЕРІАЛУ I РЕАГЕНТІВ
}

\author{
В. 3. Стецюк, Л. Ю. Бабінцева ${ }^{1}$, І. П. Муха, \\ О. Ю. Барвінська², Ю. М. Чиж \\ Національний технічний університет України \\ «Київський політехнічний інститут імені Ігоря Сікорського» \\ ${ }^{1}$ Національна медична академія післядипломної освіти імені П. Л. Шупика \\ ${ }^{2}$ Національна дитяча спеціалізована лікарня «ОХМАТДИТ»
}

Описано комп'ютерну десктопну програму для автоматизації ведення обліку хімічного посуду, реагентів і звітності про їх надходження та списання «Облік матеріалів та реагентів медичної лабораторії». Представлене програмне забезпечення дозволяє оптимізувати роботу лікарів-лаборантів і персоналу медичної лабораторії, а також забезпечує процес реєстрації, обліку та списання лабораторного витратного матеріалу та регентів.

Ключові слова: медична лабораторія, лабораторний витратний матеріал, реагенти, статистична звітність, база даних.

\section{OPTIMIZATION OF REGISTRATION AND WRITE-OFF PROCESS OF LABORATORY CONSUMABLES AND REAGENTS}

\author{
V. Z. Stetsyuk, L. Yu. Babintseva1, I. P. Muha, \\ O. Yu. Barvinska², Yu. M. Chyzh \\ National Technical University of Ukraine "Igor Sikorsky Kyiv Polytechnic Institute" \\ ${ }^{1}$ Shupyk National Medical Academy of Postgraduate Education \\ ${ }^{2}$ National Children's Specialized Hospital «OKHMATDYT»
}

The article describes the computer desktop program for automation of accounting of chemical vessels and reagents and reporting of admission and cancellation «Accounting of materials and reagents of the medical laboratory», developed to optimize the registration and write-off process of laboratory consumables and regents.

Key words: medical laboratory, laboratory consumables, reagents, statistical reporting, database.

\section{ОПТИМИЗАЦИЯ ПРОЦЕССА РЕГИСТРАЦИИ И СПИСАНИЯ ЛАБОРАТОРНОГО РАСХОДНОГО МАТЕРИАЛА И РЕАГЕНТОВ}

\author{
В. 3. Стецюк, Л. Ю. Бабинцева ${ }^{1}$, И. П. Муха, \\ О. Ю. Барвинская², Ю. М. Чиж
}

Национальный технический университет Украины «Киевский политехнический институт имени Игоря Сикорского»

${ }^{1}$ Национальная медицинская академия последипломного образования имени П. Л. Шупика

${ }^{2}$ Национальная детская специализированная больница «ОХМАТДЕТ»

Описаны компьютерную десктопную программу для автоматизации ведения учета химической посуды, реагентов и отчетности об их поступлении и списании «Учет материалов и реагентов медицинской лаборатории». Представленное программное обеспечение позволяет оптимизировать работу врачей-лаборантов и персонала медицинского лаборатории, а также обеспечивает процесс регистрации, учета и списания лабораторного расходного материала и регентов.

Ключевые слова: медицинская лаборатория, лабораторный расходный материал, реагенты, статистическая отчетность, база данных.

(c) В. З. Стецюк, Л. Ю. Бабінцева, І. П. Муха, О. Ю. Барвінська, Ю. М. Чиж 
Вступ. Робота лікаря-лаборанта $є$ важливим етапом діагностики захворювань та лікування пацієнта, оскільки саме її результати допомагають лікуючому лікарю встановити діагноз і, за потреби, направити пацієнта до спеціаліста відповідного профілю. Тому висока точність та якість результатів аналізу є важливою складовою не тільки роботи лікаря-лаборанта, а й усього процесу діагностики та лікування пацієнта.

Після вивчення проблематики сфери діяльності цієї професії виникла ідея створення комп’ютерної програми для автоматизації процесу реєстрації та списання лабораторного витратного матеріалу та реагентів. Розроблений програмний продукт передбачає оптимізацію роботи лікаря-лаборанта, оскільки забезпечує контроль за кількістю хімічного посуду та реагентів, строком придатності останніх; зменшення ймовірності виникнення помилок з обрахунками, втрат даних про рух лабораторного посуду та реагентів.

Головною перевагою впровадження програми $\epsilon$ зменшення часу на рутинну роботу з медичною документацією та оформлення прийому / списання медичних матеріалів. Саме ця перевага надає можливість, за рахунок збільшення часу, для аналітичної роботи, що забезпечує кращу точність та якість результату досліджень.

Мета дослідження: створення комп'ютерної десктопної програми «Облік матеріалів та реагентів медичної лабораторії» для оптимізації роботи клінічної лабораторії, що реалізує такі основні функції медичного документообігу та звітності: облік медичного посуду та реагентів, опис кожного виду витратного матеріалу, формування електронної звітності тощо.

Матеріал та методи дослідження. Вивчено етапи та специфіку роботи лікаря-лаборанта, зокрема біохімічні дослідження різноманітного біологічного матеріалу (крові, сечі, жовчі тощо); базу даних електронної медичної облікової документації медичної лабораторії генетики НДСЛ «ОХМАТДИТ», способи її обробки та формування необхідної звітності (з використанням основних елементів архітектури Microsoft SQL Server).

Для створення програмного забезпечення застосовували реляційну локальну базу даних формату SQL Server та основні компоненти архітектури Microsoft SQL Server 2012 Express. Для розробки програмного продукту використовували мову програмування $\mathrm{C}++$ та середовище програмування Embarcadero C++ Builder XE7. Для збереження даних розроблено відповідну реляційну локальну базу даних формату SQL Server.

Результати та їх обговорення. Одним із завдань роботи є застосування бази даних медичної документації для обліку медичних матеріалів та реагентів із метою отримання оперативної та періодичної статистичної звітності.

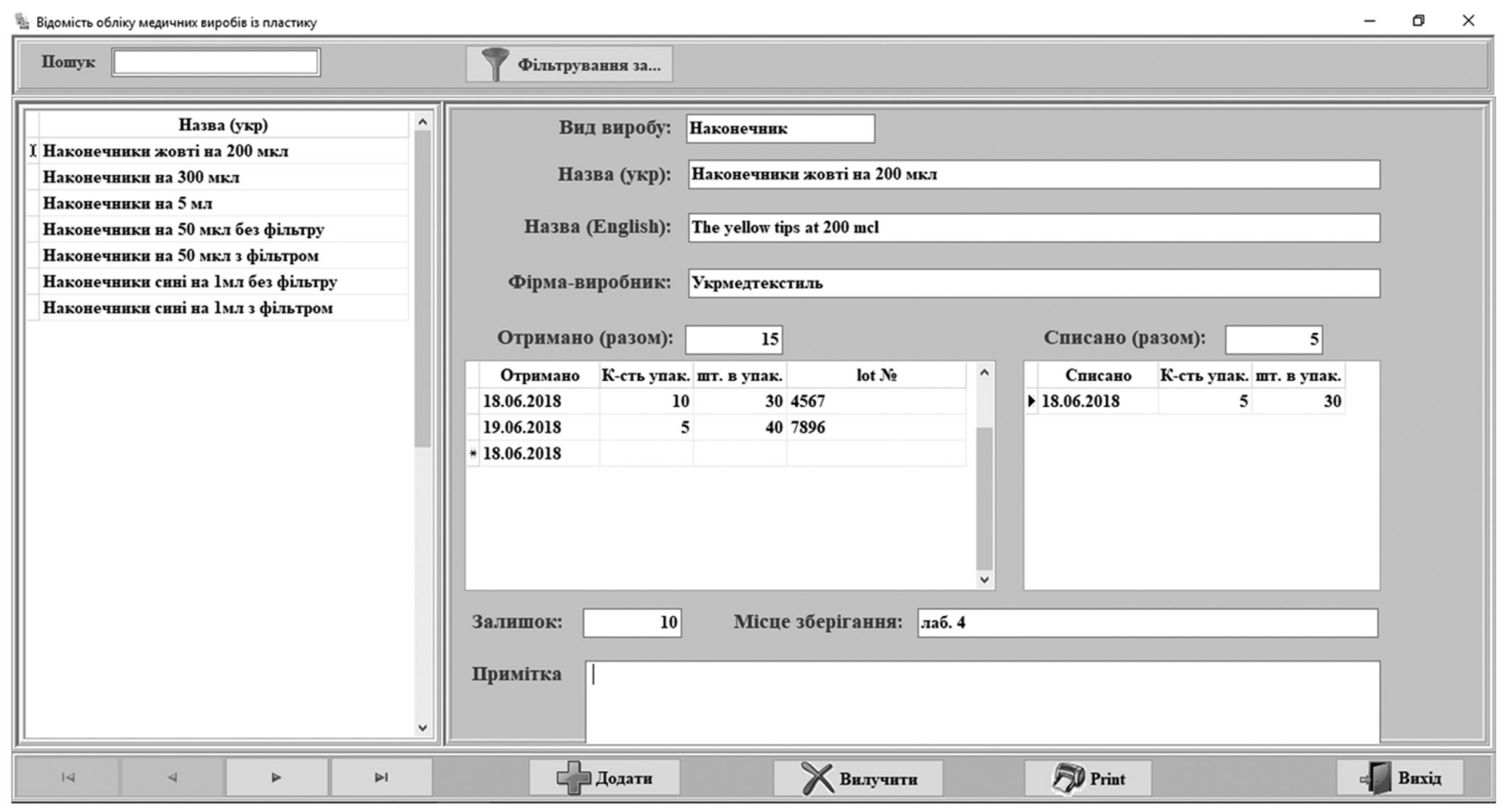

Рис. 1. Прикладна комп’ютерна програма «Облік матеріалів та реагентів медичної лабораторії» 
Результатом дослідження роботи працівників медичної лабораторії та аналізу необхідної облікової документації став програмний продукт, що оптимізує роботу персоналу лабораторії.

Прикладна комп’ютерна програма «Облік матеріалів та реагентів медичної лабораторії» (рис. 1) встановлюється на одному комп’ютері медичної лабораторії. Оператором даної програми є лікарлаборант, який веде облік медичних матеріалів і реактивів. Запропонований програмний продукт забезпечує створення медичної та статистичної звітності.

Програма реалізує такі функції:

- облік виробів залежно від виду (скло, пластик) та підкатегорії;

- динамічне керування наявністю підкатегорій для кожного виду виробів;

- оформлення надходження та списання кожного виробу та реагенту;

- збереження основної інформації про кожен виріб;

- автоматичний контроль над залишком залежно від отримання / списання кожного виробу;

- контроль за строком придатності кожного отриманого реагенту;

- формування звітності за вказані періоди з можливістю перегляду та друку інформації за певними показниками.

Користувач програми може виконувати такі основні дії:

• перегляд відомостей по кожному виду виробів та реагентів;

\section{Література.}

1. Бьюли А. Изучаем SQL / А. Бьюли ; пер. с англ. СПб : Символ-Плюс, 2007. - 312 с.

2. Романчик В. С. Программирование в С++ Builder / В. С. Романчик, А. Е. Люлькин. - Минск, 2007. $128 \mathrm{c}$.

3. Эккель Б. Философия С++. Введение в стандартный С++ / Б. Эккель, Ч. Эллисон. - СПб : Питер, 2004. -577 c.

4. Guyer С. Документация по SQL Server [Электронный pecypc] / C. Guyer. - Сайт docs.microsoft.com - Peжим доступа : https://goo.gl/VrWkUY.

5. Стецюк В. 3. Використання ERP-систем для медичних установ / В. З. Стецюк, Т. П. Іванова, Л. Ю. Бабінцева, Н. В. Ольхович, М. М. Лугін, О. Д. Фіногенов // Медична інформатика та інженерія. 2017. - № 4. - C. 44-47. doi: http://dx.doi.org/10.11603/ mie.1996-1960.2017.4.8451.
- пошук виробу або реагенту за його назвою;

- фільтрація виробів за назвою (українською та англійською), видом, виробником;

- створення / видалення нової підкатегорії для кожного виду виробу;

- можливість друку таких відомостей:

- деталізований звіт (звіт, який містить всю інформацію про вироби даного виду);

- реєстр надходження за вказаний період;

- реєстр списання за вказаний період.

Зауважимо, що набір потрібних для формування звітів даних можна комбінувати. А при перегляді більшості відомостей $є$ можливість звернення до первинної облікової медичної документації. Зручним для роботи лікаря-лаборанта є це одна функція, що дозволяє перегляд і друкування раніше сформованих звітів як у табличній формі, так і у вигляді діаграм.

\section{Висновки.}

Представлений програмний продукт забезпечує оптимізацію роботи лікаря-лаборанта та всього персоналу медичної лабораторії, оскільки створений перш за все для автоматизації ведення обліку хімічного посуду, реагентів і звітності про їх надходження та списання.

Результати проведеної апробації програми вказують на високу ефективність її впровадження.

\section{References.}

1. Beaulieu, A. (2007). Izuchaem SQL [Learning SQL]. St. Petersburg: Simvol-Pljus.

2. Romanchik, V. S., Ljul'kin A. E. (2007). Programmirovanie v S++ Builder. Minsk.

3. Eckel, B., Allison, C. (2004). Filosofija C++. Vvedenie v standartnyj C++ [Thinking in C++ Volume Two: Practical Programming]. St. Petersburg: Piter.

4. Guyer, C. (2018, Aug 10). Dokumentacija po SQL Server [SQL Server Documentation]. Retrieved from: https:// goo.gl/VrWkUY.

5. Stetsyuk, V. Z., Ivanova, T. P., Babintseva, L. Yu., Olkhovych, N. V., Lugin, M. M., Finogenov, O. D. (2017). Vykorystannya ERP-system dlya medychnyh ustanov [Using ERP-systems for medical institutions]. Medichna informatika ta inzheneriya (Medical Informatics and Engineering), 4, 44-47. doi: http:// dx.doi.org/10.11603/mie.1996-1960.2017.4.8451. 